\title{
Creatividad en publicidad. Del impacto al comparto
}

Creativity in advertising. From impact to share

Fechas | En edición: 17/07/2018 - Publicación final: 01/01/2019

\section{Dra. Carmen LLORENTE-BARROSO}

Universidad Complutense de Madrid. España. carmenllorente@ucm.es

\section{Creatividad en publicidad. Del impacto al comparto}

Francisco GARCÍA-GARCÍA; Victoria TUR-VIÑES; Isidoro ARROYOALMARAZ Y LUIS RODRIGO-MARTíN.

Madrid: Dykinson, 2018

435 páginas

ISBN: 978-84-9148-567-4

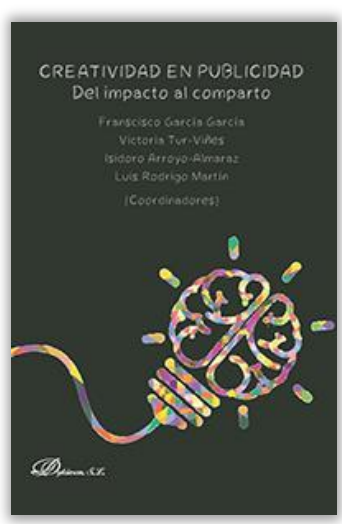

\section{Resumen}

El texto que se reseña se focaliza en la creatividad publicitaria, orientándose a un público muy diverso con especial interés por este particular objeto de estudio. Con una estructura limpia y clara hace un recorrido por las líneas de investigación que tradicionalmente se han aplicado al estudio de la creatividad, pero focalizadas específicamente en materia publicitaria. Sujeto, proceso, producto y entorno creativos se convierten en los encabezados de los cuatro apartados temáticos de esta obra, que condensa, en 17 capítulos, perspectivas muy interesantes sobre aspectos concretos de la creatividad publicitaria.

\section{Palabras clave}

Creatividad; entorno creativo; proceso creativo; producto creativo; publicidad; sujeto creativo.

\begin{abstract}
This work which is reviewed focuses on advertising creativity. It is targeting at a very diverse audience with special interest in this particular object of study. With a clean and clear structure, it goes through the research lines that have traditionally been applied to the study of creativity, but specifically focused on advertising. Creative person, process, product and environment become the headings of the four thematic sections of this book, which condenses, in 17 chapters, very interesting perspectives on particular topics of advertising creativity.
\end{abstract}

\section{Keywords}

Advertising; creative environment; creative person; creative process; creative product; creativity. 
Creatividad en publicidad. Del impacto al comparto conforma un libro esencial para el amante de la creatividad publicitaria. Coordinado por cuatro de los grandes referentes de la creatividad aplicada a la comunicación persuasiva, Francisco García-García, Victoria Tur-Viñes, Isidoro Arroyo-Almaraz y Luis Rodrigo-Martín, la obra refleja calidad y rigor en cada uno de los capítulos que componen sus cuatro bloques temáticos y que firman diferentes profesores universitarios de mencionado campo.

El interés por la creatividad se ha focalizado, tradicionalmente, en cuatro grandes aspectos que la caracterizan y la determinan; persona creativa, proceso creativo, producto creativo y entorno creativo han sido objeto de las múltiples investigaciones que se han desarrollado en materia de creatividad desde la perspectiva científico-académica, que ha aportado, especialmente, la Psicología. Al respecto, Creatividad en publicidad. Del impacto al comparto, presenta una estructura perfectamente adaptada a la evolución en el desarrollo de mencionados estudios. Consecuentemente, sus cuatro bloques temáticos reflejan de forma completa y oportuna las grandes líneas de la investigación que se han desarrollado en torno a la creatividad como objeto de estudio de capital importancia para diferentes disciplinas. Si bien, no es un aspecto que se haya considerado habitualmente en la perspectiva analítica publicitaria, por lo que esta estructura ya presenta un elemento de originalidad a destacar, que además, refuerza el carácter científico-académico de la obra, pues el análisis y la difusión de resultados sobre la investigación en creatividad publicitaria, generalmente, se ha apoyado en el matiz más estratégico de esta forma de comunicación. De este modo, se puede reseñar que la obra representa un destacado interés investigador por la creatividad aplicada al campo de la publicidad.

Si se hace un recorrido por cada una de sus cuatro partes se descubrirá la diversidad de puntos de vista y el acertado tratamiento de objetos de estudio particulares dentro de estas cuatro grandes líneas que han estudiado la creatividad, pero en este caso, aplicadas a la publicidad.

La primera parte, dedicada al productor de la creatividad, al sujeto creativo, analiza en tres capítulos las cualidades del creativo publicitario y la manera de incentivar sus capacidades desde la universidad y el juego. Estas aportaciones emergen como necesarias, dado que en las dificultades del aula "no es fácil reconducir o potenciar la confianza de unos, motivar a otros, y al mismo tiempo que todos aprendan a lidiar con sus propios miedos" (Ramos-Serrano, 25), y en el espacio profesional, "el apoyo emocional de los colegas del equipo se hace fundamental para superar todos los rechazos" (Roca, 45).

La segunda parte, focalizada en el análisis del proceso creativo, incluye estudios sobre aspectos muy específicos y actuales de la creatividad publicitaria, pero también propuestas que exploran planteamientos de análisis académicos que resaltan por su originalidad. Así, a lo largo de los siete capítulos de este bloque, se percibe el interés por imprescindibles actuales como el concepto de insight, la importancia del storytelling o el valor de la experiencia, sin olvidar la clave de la ideación y la redacción ante el reto virtual, al tiempo que se propone la retórica como método para lograr una poética de la publicidad, y otros métodos más clásicos en el ámbito publicitario, pero no menos oportunos y necesarios. La importancia de comprender el insight para el desarrollo de una estrategia que responda a esa "experiencia de descubrimiento o revelación" (Castelló-Martínez, 97) o el encuentro y aprovechamiento de la poética como "una relación muy productiva entre retórica y creatividad, en un ejercicio constante entre la ruptura creativa y la normalidad retórica" (García-García, 144) se alzan como dos propuestas completamente diferentes, pero igual de interesantes en esta parte de la obra.

El tercer bloque temático, con cuatro capítulos dedicados al análisis del producto creativo, ofrece interesantes puntos de vista sobre los mensajes publicitarios y su importancia para los creativos que los construyen y las marcas que los utilizan. Con el peculiar producto creativo publicitario como objeto de estudio, y considerando la dificultad añadida que supone, pues su mayor valor es intangible, se realiza una brillante aproximación a aspectos de capital importancia en la persuasión publicitaria y su expresión visual a través de la dirección de arte y la carpeta creativa. Se pone hincapié en la importancia de la efectividad de los mensajes, apuntándose que es una característica "inherente a la propia definición de creatividad y no debería ser considerada como una dimensión aparte" (Tur-Viñes, 270). El guiño al valor inmaterial de los mensajes, se vincula a la propia significación que de los mismos haga el target, ya que "la imagen publicitaria no funciona como una proposición cerrada, su interpretación depende de la predisposición del receptor a realizar un 'cálculo interpretativo'" (Rom-Rodríguez, 350).

Para finalizar, el entorno creativo, es el bloque temático que cierra esta propuesta con tres capítulos que hacen un recorrido por la determinación del contexto en el ámbito de la creatividad y la publicidad. El espacio creativo ha sido en sí un elemento de motivación y generación de ideas en el sector publicitario, por ello los departamentos de creatividad publicitaria han respondido a licencias de mayor flexibilidad. Actualmente, a este hecho tradicional, se suman nuevas necesidades; los nuevos retos de las marcas por lograr una generación de contendidos que haga partícipe a sus públicos han condicionado nuevas metodologías de trabajo y replanteamientos estructurales en los departamentos creativos que superan a 
las propias agencias. Hoy se busca en el público una respuesta positiva, que lejos de "estorbar su experiencia", aporte valor a la misma (Blay-Arráez; Balado-Albiol y Zomeño-Jiménez, 375). Al mismo tiempo, este bloque no se olvida de la importancia que tiene el fomento de la creatividad desde la infancia y con el apoyo en la educación, considerando que los contextos educativos "que favorecen el desarrollo de la creatividad deben proporcionar situaciones, tiempos, espacios, materiales y oportunidades para que puedan plantear acciones educativas que se transformen en producciones creativas" (Núñez-Gómez; Rodrigo-Martín y Rodrigo-Martín, 402). Finalmente, se estudian los desafíos y las oportunidades en una particular materia creativa en publicidad, la dirección de arte, que ha fomentado el interés por la expresión visual de los conceptos creativos en la era de los impactos visuales.

En definitiva, una obra de gran valor científico-académico que agradecerán investigadores, profesores y alumnos, apasionados por el mundo de la creatividad aplicada a la publicidad. Esta cualidad se complementa con su carácter pedagógico y su calidad didáctica; su tono ameno y los ejercicios que se incluyen al final de cada capítulo ayudarán a los estudiantes a asimilar mejor los conceptos que se abordan.

Esta propuesta, fruto de la colaboración entre varios expertos en creatividad publicitaria, ofrece también una oportunidad a la reflexión en una materia tan destacada como la creatividad aplicada a un sector castigado por las crisis y necesitado de nuevas propuestas. 
